\title{
Finite Element Analysis of Opening Plate, Fixed Tube Sheet and Floating Sheet of Shell \& Tube Heat Exchanger
}

\author{
Nishant Agnihotri ${ }^{1}$, Praveen Singh ${ }^{2}$ \\ (Department of Mechanical Engineering, Barkatullah University Institute of Technology Bhopal, India).
}

\begin{abstract}
A$ heat exchanger is a device that is used to transfer thermal energy (enthalpy) between two or more fluids, between a solid surface and a fluid, or between solid particulates and a fluid, at different temperatures and in thermal contact. Opening Plate, Fixed Tube Sheet and Floating Tube Sheet is a part of Shell \& Tube Heat Exchanger, used in refinery and oil \& gas production. Typically, shell \& tube heat exchanger can be considered as a pressure vessel subjected to uniform internal pressure. Hence the shell \& tube heat exchanger in various design and operating conditions needs to be checked and verified for soundness of participating components. Opening, Fixed tube and Floating sheet plate due to uniform internal pressure in the shell \& tube heat exchanger can produce high-localized stress and deformation. If the components are not designed for these conditions, safety of the equipment is at stake. Hence check for the stress and displacement of the shell \& tube heat exchanger during operating condition is carried out using finite element analysis software and observed that shell \& tube heat exchanger is free from collapse and serviceability failure.
\end{abstract}

\section{Introduction}

${ }^{(2)}$ Heat exchangers are systems that transfer heat between fluid mediums. The fluids or gases in a heat exchanger can be mixed or the energy transference can go through a conductive wall that keeps them separate. Structural integrity of the shell \& tube heat exchanger box can be checked by using ${ }^{(13)}$ Appendix 13 of ASME Sec VIII Div I and other parts of the shell \& tube heat exchanger box with the respective clauses of ASME code. For installing the shell \& tube heat exchanger box opening is made on it, this opening of the vessel must be reinforced with an equal amount of metal which has been cut out for the opening. The reinforcement may be an integral part of the vessel may be an additional reinforcing pad. In addition the compensation must account for the bending strength as well as the membrane strength. The reinforcement calculations for openings according to UG-39 are required in addition to bending \& membrane strength. However, the calculation of "Area required', according to UG-39, requires that the 'required thickness'(tr) be substituted for in the formula, and it has not been calculated, since the method used in Appendix 13 is by assuming a thickness and calculating stresses then comparing with allowable stresses and yield stress. This means that 'required thickness' (tr) cannot be directly calculated. Accordingly, the required area 'A' cannot be directly calculated however in this case nozzle opening is larger than $1 / 2$ of the shell \& tube heat exchanger opening hence is beyond the scope of UG-39 of ASME Sec VIII Div-I and therefore the calculation has to done by finite element method.

\section{About Shell \& Tube Heat Exchanger}

Shell \& tube heat exchanger is used where differential temperature between two passes exceeds 111 deg C. Shell \& tube heat exchangers are type of tapped cover shell \& tube heat exchangers which are made in two different pressure compartments such that each compartment has geometry to allow only one pass of fluid to pass through it. Shell-and-tube heat exchangers are used widely in the chemical process industries, especially in refineries, because of the numerous advantages they offer over other types of heat exchangers. A lot of information is available regarding their design and construction. The present notes are intended only to serve as a brief introduction. Mechanical standards for shell-and-tube heat exchangers are set by TEMA (Tubular Exchangers Manufacturers Association) and these supplement the ASME code for such heat exchangers. API (American Petroleum Institute) Standard 660 supplements both of these standards, and chemical and petroleum companies also have their own internal standards in addition. Advantages Here are the main advantages of shelland-tube heat exchangers

It is also designed as per ASME Sec VIII Div 1 Mandatory Appendix 13 and API-661. Further differential tube expansion due to shell \& tube heat exchanger movement is calculated which depends upon operating temperature and metallurgy used.

\subsection{About The Company}

${ }^{(20)}$ GEI Industrial Systems Ltd was established in the year 1970 in the city of Bhopal in the Central Indian State of Madhya Pradesh. GEI Industrial Systems Ltd is a leader in heat transfer technology for more 
than 40 years and specializes in the design, manufacture, fabrication, testing, and erection \& commissioning of Air Cooled Heat Exchangers for Oil, Gas and Power sector and Air Cooled Vacuum Steam Condensers for Steam Turbine Power Plants. GEI is an ISO 9001-2008 certified company and follow Quality Management Systems for the entire business process right from the basic design to manufacturing and installation at the site. GEI holds U stamp certification; The National Board of Boilers and Pressure Vessel Inspector have provided R stamp certification and NB Marking. More than 4000 bundles of Air Cooled Heat Exchanger and Air Cooled Steam Condenser are operating in India and abroad in the oil, gas and power sector in more than 18 countries worldwide. GEI heat transfer products are operating across the globe in the regions of Africa, Americas, Asia, Europe and Oceania. GEI is today one of the leading Engineering and Manufacturing Company dealing with heat transfer equipments with a major thrust in Air Cooled Heat Exchangers and Air Cooled Steam Condensers. The Air Cooled Heat Exchangers are used for cooling of hot fluids using atmospheric air in the Oil and Gas Exploration, Production, Refining and Petrochemical Industry and also in the power plants as dry cooling tower as a replacement of conventional wet type cooling towers.

Air Cooled Vacuum Steam Condensers are revolutionary product being used in steam turbine power plants thereby eliminating Water Cooled Steam Condenser and Cooling Towers which consumes lot of water.

${ }^{(20)}$ GEI has a total factory area of about 34.5 acres spread at two locations namely in Govindpura and Mandideep near Bhopal. The total manpower strength of GEI is 650 which include qualified professional and experience workmen trained in various disciplines right from Basic Design, Detailed Design and Engineering, Procurement, Project Monitoring, Production Planning, Manufacturing, Quality Control, Logistics, Site Services and support functional like Finance, HR, Safety and Maintenance. Heat transfer products designed manufactured and supplied by GEI have been installed at different locations around the Globe and are performing satisfactory at different locations in Africa, Europe, Middle East, South East and Far East Asian countries and in the Americas.

\subsection{Geometrical Parameter}

\section{Geometrical, Material Parametres And Design Data}

The 3-Dimensional Shell form model of the shell \& tube heat exchanger in corroded condition is considered for loading. The Dimension of the Top/Bottom plate of shell \& tube heat exchanger is of 90.985 inch length,1.378 inch thickness and width is 8.859 inch. For DN $150 \mathrm{SCH} 160$ nozzle Pipe circular size 152.4 O/D Thickness $41.3 \mathrm{~mm}$.

\subsection{Unit Used}

Displacement: mm

Pressure: $\mathrm{MPa}$

Mass: Tonne

Density: Tonne/mm^3

\subsection{Material}

The material used is SA 516 Gr.485 for opening plates and SA 182 Gr. F316L for fixed tube sheet and floating tube sheet for which material properties are accounted

$\begin{array}{ll}\text { Opening Plate } & : \text { SA-516M, Gr. } 485 \\ \text { Young's modulus } & : 1.956 \mathrm{E} 5 \mathrm{MPa} \\ \text { Poisson Ratio } & : 0.3 \\ \text { Density } & : 7750 \mathrm{Kg} / \mathrm{m}^{\wedge} 3\end{array}$

Fixed Tube Sheet: SA-182, Gr. 316L

$\begin{array}{ll}\text { Young's modulus } & : 1.866 \mathrm{E} 5 \mathrm{MPa} \\ \text { Poisson Ratio } & : 0.3 \\ \text { Density } & : 7750 \mathrm{Kg} / \mathrm{m}^{\wedge} 3 \\ & \\ \text { Floating Tube Sheet } & : \text { SA-182, Gr. } 316 \mathrm{~L} \\ \text { Young's modulus } & : 1.866 \mathrm{E} 5 \mathrm{MPa} \\ \text { Poisson Ratio } & : 0.3 \\ \text { Density } & : 7750 \mathrm{Kg} / \mathrm{m}^{\wedge} 3\end{array}$

Material properties are taken from ASME Sec II-D.

\subsection{Restraint And Load Conditions.}


In order to restraint the model correctly, a $200 \mathrm{~mm}$ portion of the shell is modeled. A cylindrical coordinate system is created at the center of the shell. The area of the shell, shown in red, is restrained in the longitudinal direction and in the theta direction. It is allowed to move in the radial direction.

\section{Case 1 - Shell Side Pressure}

The inner wall of the opening plate is applied with the pressure of 2.099 MPa. This is shown in blue color and green color. Direction of pressure is shown by arrows.

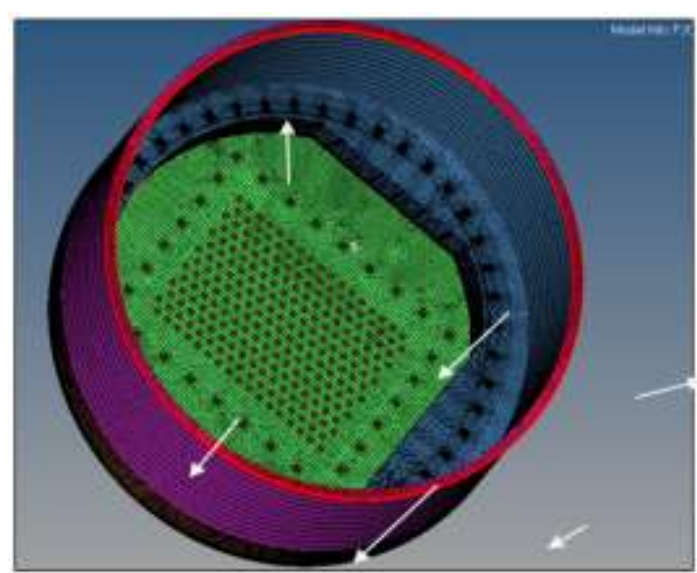

Figure. 1

\section{Case 2 - Water Box Side Pressure}

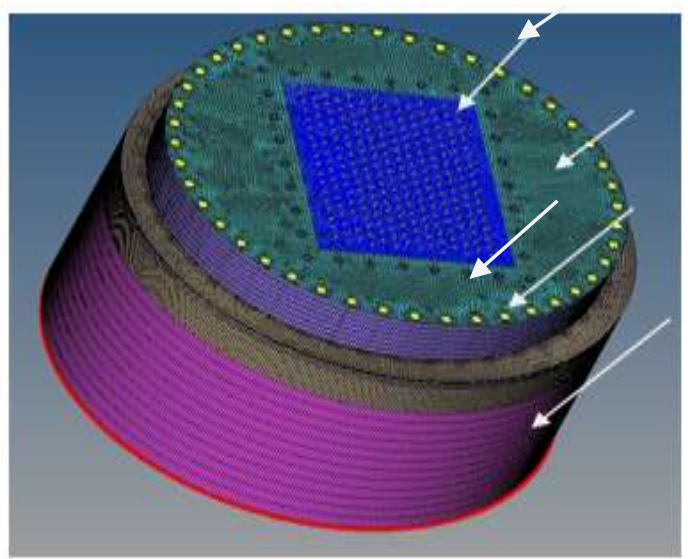

Figure. 1

A pressure of $0.941 \mathrm{MPa}$ is applied on the face of the fixed tube sheet - shown in blue The direction of pressure is shown by arrows.

Case 3 - Combined Shell And Water Box Side Pressure

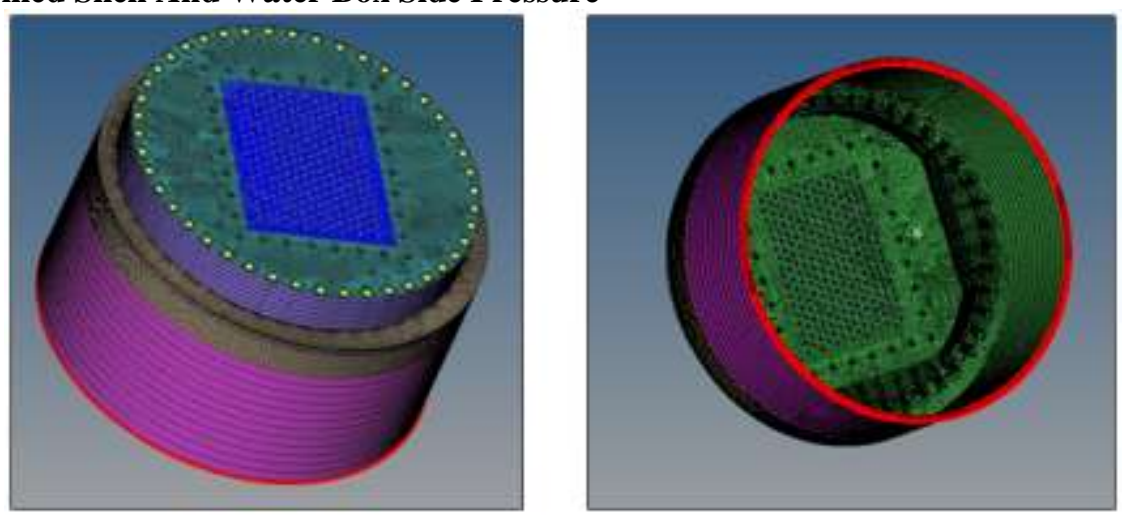

Figure. 3 
The inner wall of the opening plate is applied with the pressure of 2.099 MPa. This is shown in green color. A pressure of $0.941 \mathrm{MPa}$ is applied on the face of the fixed tube sheet - shown in blue The direction of pressure is shown by arrows in the earlier figures.

\section{Finite Element Modeling}

The analysis is performed using finite element analysis computer program. The model is meshed with shell mesh elements, finite element length 10. Elements have a constant state of strain or stress over the integration domain. Elements are more preferable to accurately capture the variation in the result (stress, strain and displacement) across the part. The model is meshed all over. The thickness of the different mesh of the model is changed to take care of varying thickness of shell \& tube heat exchanger top plate and nozzle. As the shell \& tube heat exchangers top plate and nozzle is analysed for FEA analysis, which is welded on the edge surface of tube sheet, plug sheet $\&$ end plates. So the top plate behaves as a shell member with all its surface edges restrained. ${ }^{(13)}$ The stress evaluation is performed as per Appedix-4 of ASME Code Section VIII, Div 2, Ed 2004 addenda 2006 at pressure max. 1200psi. The primary and primary plus secondary stress intensities are checked at top middle and bottom shell of the plate and displacement evolution has been carried out for the same model.

\subsection{Boundary Conditions}

As the shell and tube is analyzed for FEA analysis, which is welded on the edge surface of tube sheet, So the opening plate sheet and fixed plate sheet with all its surface edges. Hence, the restraint condition of the holes of opening sheet and fixed sheet is $U x=0, U z=0, U y=0, R x=R y=R z=0$ The shell \& tube heat exchanger are connected with pipe lines during operation part from load due to internal pressure, plates are subjected to external forces and moments applied simultaneously. It is assumed that the external forces and moments are 2 times of API allowable load for nozzles \& shell \& tube heat exchanger. For simplicity, analysing at the steady state position simulates the loading of the shell \& tube heat exchanger.

\subsection{Criteria Of Acceptability}

The acceptance criteria are as per ASME VIII, Div. 2.

"Design based on stress analysis".

1. Stress intensity derived from the average value across the thickness of a section of the General Primary Stress $(\mathrm{Pm})$ produced by internal pressure and other loads but excluding geometrical discontinuities and all secondary and peak stresses must be less than $\mathrm{Sm}$; where $\mathrm{Sm}$ is the allowable stress intensity of material at design temperature.

2. Stress intensity derived from the average value across the thickness of a section of the Local Primary Stress (PL) produced by internal pressure and other loads including geometrical discontinuities but excluding all secondary and peak stresses must be less than $1.5 \mathrm{Sm}$.

3. Stress intensity derived from the average value across the thickness of a section of the Local Primary membrane stress plus primary stress proportional to distance from centroid produced only by mechanical load $((\mathrm{PL}+\mathrm{Pb})$ must be less than $1.5 \mathrm{Sm}$.

4. Stress intensity derived from the addition of local primary membrane equivalent stress, secondary bending equivalent stress \& secondary equivalent stress $((\mathrm{PL}+\mathrm{Pb}+\mathrm{Q})$ across the thickness of a section must be less than $3 \mathrm{Sm}$.

\subsection{Stress Linearization Of Opening Plate, Fixed Tube And Floating Tube Sheet}

The acceptance criterion is as per ASME VIII, Div2, Ed 2010 Design by Analysis requirement:

- General Primary Membrane Equivalent Stress (Pm) :

Equivalent stress derived from the average value across the thickness of a section of the General Primary Stress $(\mathrm{Pm})$ produced by internal pressure and other mechanical loads but excluding geometrical discontinuities and all secondary and peak stresses must be less than $\mathrm{S}$; where $\mathrm{S}$ is the allowable stress of material at design temperature.

- $\quad$ Primary Membrane (General or Local) Plus Primary Bending Equivalent

Stress $(\mathrm{PL}+\mathrm{Pb})$ :

Equivalent stress derived from the average value across the thickness of a section of Local primary membrane stress plus primary stress proportional to distance from centroid produced only by mechanical load $(\mathrm{PL}+\mathrm{Pb})$ must be less than $1.5 \mathrm{~S}$. 


\subsubsection{Opening Plate- Scl Lines}
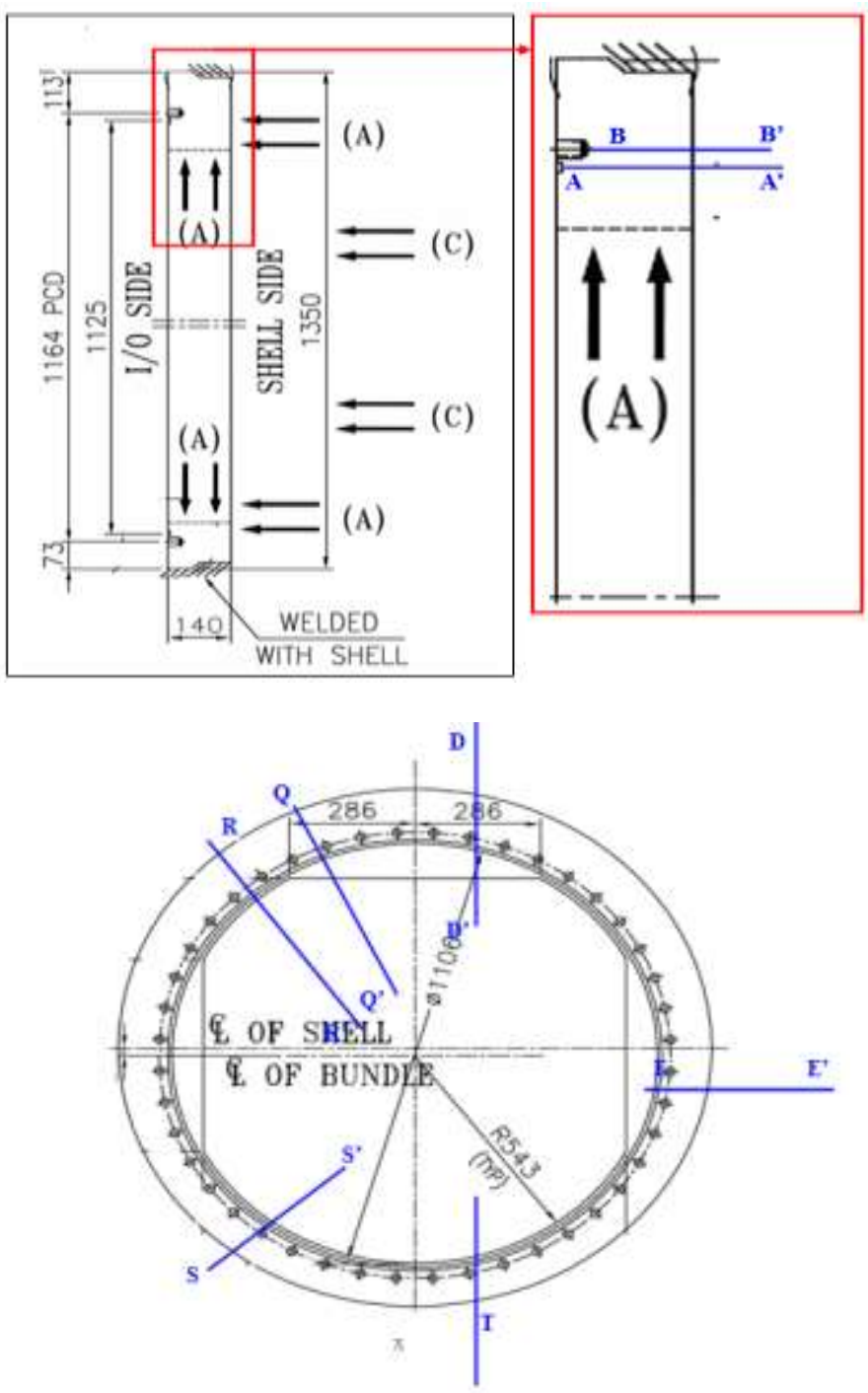

Figure. 4

\subsubsection{Fixed Tube Sheet- Scl Lines}

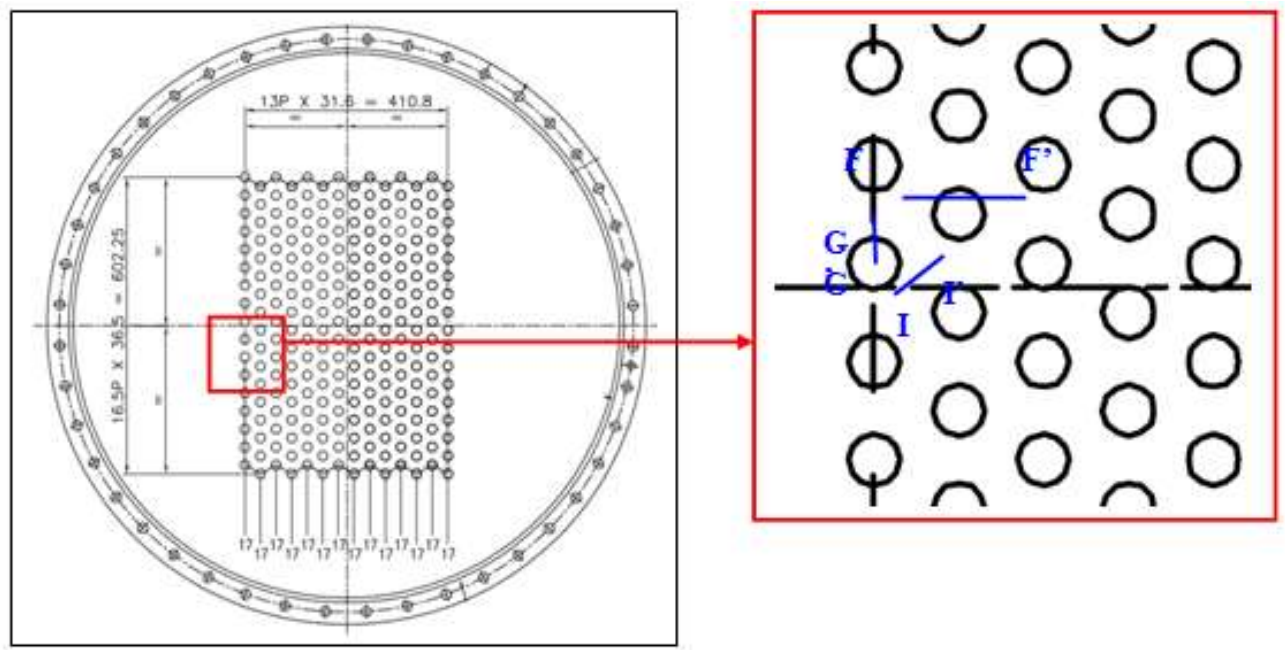




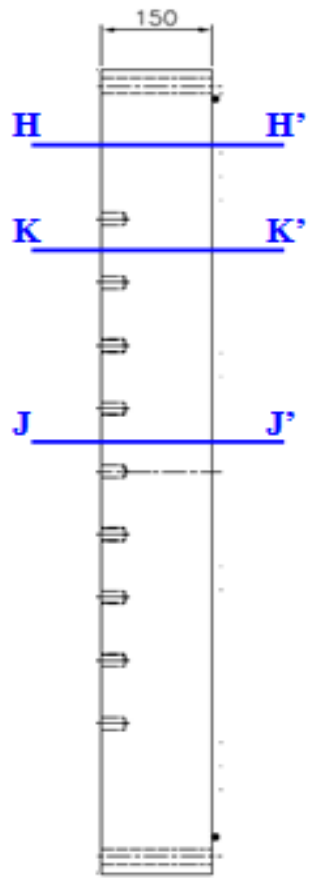

Figure. 5

\subsubsection{Floating Tube Sheet- Scl Lines}
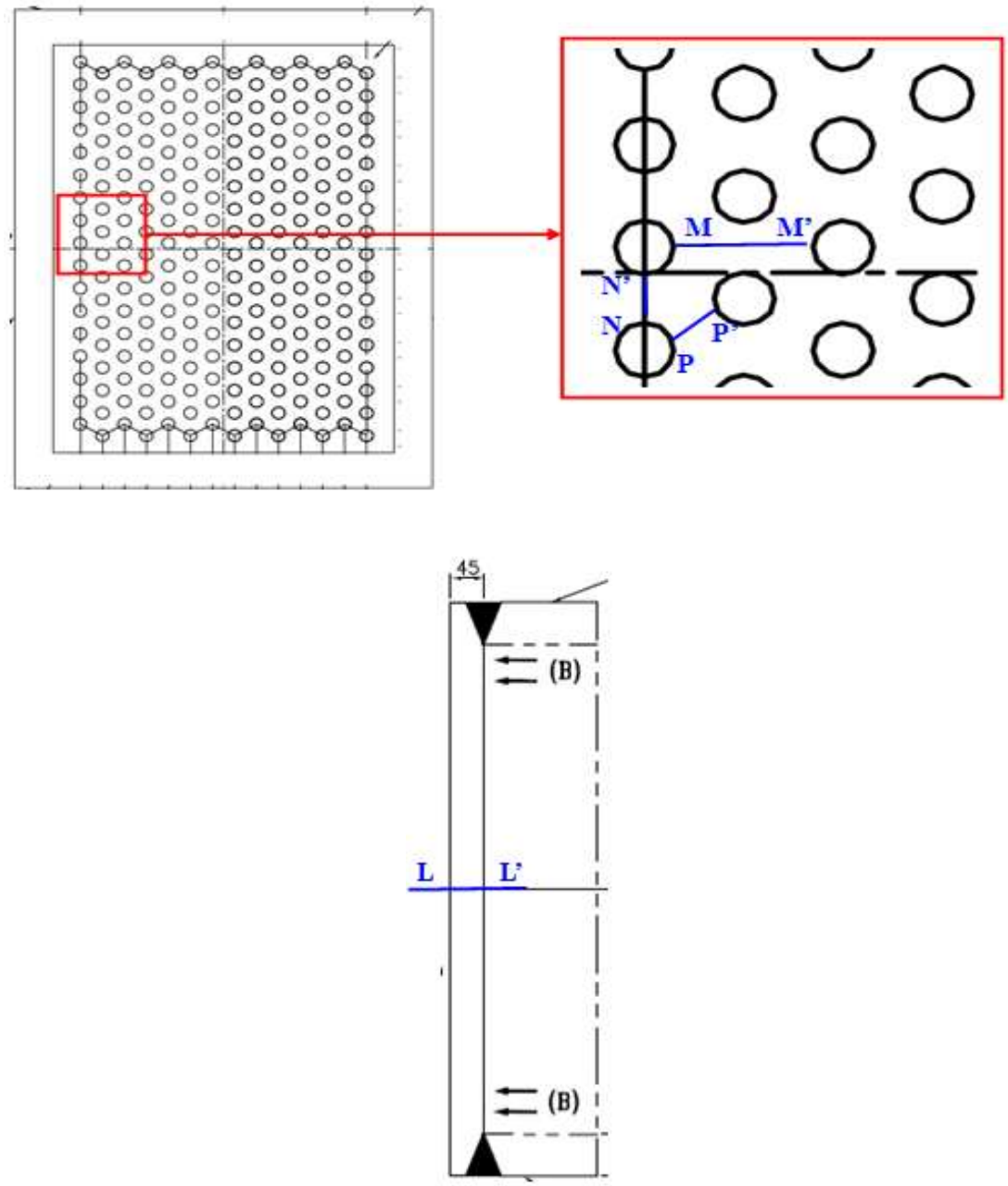

Figure. 6 


\section{Result \& Conclusion}

Case 1 - Shell Side Pressure

\begin{tabular}{|c|c|c|c|c|c|c|}
\hline SCL & Location & $\begin{array}{l}\text { Membrane } \\
(\mathrm{Pm})(\mathrm{MPa})\end{array}$ & $\begin{array}{l}\text { Allowable } \\
\text { Limit (MPa) }\end{array}$ & $\begin{array}{lr}\begin{array}{l}\text { Membrane } \\
\text { Bending } \\
(\mathrm{MPa})\end{array} & \left(\mathrm{P}_{\mathrm{L}}+\mathrm{Pb}\right) \\
\end{array}$ & $\begin{array}{l}\text { Allowable Limit } \\
(\mathrm{MPa})\end{array}$ & Comment \\
\hline$A-A^{\prime}$ & Opening Plate & 8.62 & 138.00 & 33.56 & 207.00 & Safe \\
\hline$B-B^{\prime}$ & Opening Plate & 11.65 & 138.00 & 30.77 & 207.00 & Safe \\
\hline $\mathrm{D}-\mathrm{D}^{\prime}$ & Opening Plate & 8.23 & 138.00 & 12.54 & 207.00 & Safe \\
\hline$E-E^{\prime}$ & Opening Plate & 11.49 & 138.00 & 17.61 & 207.00 & Safe \\
\hline$Q_{-}-Q^{\prime}$ & Opening Plate & 34.32 & 138.00 & 43.52 & 207.00 & Safe \\
\hline $\mathrm{R}-\mathrm{R}^{\prime}$ & Opening Plate & 31.43 & 138.00 & 36.29 & 207.00 & Safe \\
\hline $\mathrm{S}-\mathrm{S}^{\prime}$ & Opening Plate & 30.56 & 138.00 & 35.11 & 207.00 & Safe \\
\hline $\mathrm{T}-\mathrm{T}^{\prime}$ & Opening Plate & 27.10 & 138.00 & 27.93 & 207.00 & Safe \\
\hline$F-F^{\prime}$ & Fixed TS & 6.79 & 88.96 & 7.07 & 133.44 & Safe \\
\hline $\mathrm{G}-\mathrm{G}^{\prime}$ & Fixed TS & 8.27 & 88.96 & 8.96 & 133.44 & Safe \\
\hline $\mathrm{H}-\mathrm{H}^{\prime}$ & Fixed TS & 5.47 & 88.96 & 22.11 & 133.44 & Safe \\
\hline$I-I^{\prime}$ & Fixed TS & 9.42 & 88.96 & 9.46 & 133.44 & Safe \\
\hline $\mathrm{J}-\mathrm{J}^{\prime}$ & Fixed TS & 1.91 & 88.96 & 39.67 & 133.44 & Safe \\
\hline $\mathrm{K}-\mathrm{K}^{\prime}$ & Fixed TS & 5.32 & 88.96 & 31.03 & 133.44 & Safe \\
\hline L-L' & Floating TS & 2.57 & 88.96 & 68.32 & 133.44 & Safe \\
\hline $\mathrm{M}-\mathrm{M}^{\prime}$ & Floating TS & 19.86 & 88.96 & 26.11 & 133.44 & Safe \\
\hline $\mathrm{N}-\mathrm{N}^{\prime}$ & Floating TS & 40.47 & 88.96 & 40.57 & 133.44 & Safe \\
\hline $\mathrm{P}-\mathrm{P}^{\prime}$ & Floating TS & 21.35 & 88.96 & 28.51 & 133.44 & Safe \\
\hline
\end{tabular}

Case 2 - Water Box Side Pressure.

\begin{tabular}{|c|c|c|c|c|c|c|}
\hline SCL & Location & $\begin{array}{l}\text { Membrane Stress } \\
(\mathrm{Pm})(\mathrm{MPa})\end{array}$ & $\begin{array}{l}\text { Allowable Limit } \\
(\mathrm{MPa})\end{array}$ & $\begin{array}{l}\text { Membrane + Bending } \\
\left(\mathrm{P}_{\mathrm{L}}+\mathrm{Pb}\right)(\mathrm{MPa})\end{array}$ & $\begin{array}{l}\text { Allowable Limit } \\
(\mathrm{MPa})\end{array}$ & Comment \\
\hline $\mathrm{A}-\mathrm{A}^{\prime}$ & Opening Plate & 1.84 & 138.00 & 13.38 & 207.00 & Safe \\
\hline $\mathrm{B}^{-\mathrm{B}^{\prime}}$ & Opening Plate & 6.36 & 138.00 & 15.33 & 207.00 & Safe \\
\hline$E-E^{\prime}$ & Opening Plate & 10.06 & 138.00 & 11.13 & 207.00 & Safe \\
\hline${\mathrm{Q}-\mathrm{Q}^{\prime}}^{\prime}$ & Opening Plate & 12.95 & 138.00 & 15.33 & 207.00 & Safe \\
\hline $\mathrm{R}-\mathrm{R}^{\prime}$ & Opening Plate & 11.94 & 138.00 & 12.58 & 207.00 & Safe \\
\hline $\mathrm{T}-\mathrm{T}^{\prime}$ & Opening Plate & 9.50 & 138.00 & 10.22 & 207.00 & Safe \\
\hline$F-F^{\prime}$ & Fixed TS & 2.80 & 88.96 & 2.83 & 133.44 & Safe \\
\hline $\mathrm{G}-\mathrm{G}^{\prime}$ & Fixed TS & 3.84 & 88.96 & 3.87 & 133.44 & Safe \\
\hline $\mathrm{H}-\mathrm{H}^{\prime}$ & Fixed TS & 1.66 & 88.96 & 13.19 & 133.44 & Safe \\
\hline I- I' & Fixed TS & 3.16 & 88.96 & 3.32 & 133.44 & Safe \\
\hline $\mathrm{J}-\mathrm{J}$ & Fixed TS & 0.66 & 88.96 & 20.39 & 133.44 & Safe \\
\hline $\mathrm{N}-\mathrm{N}^{\prime}$ & Floating TS & 19.44 & 88.96 & 19.56 & 133.44 & Safe \\
\hline $\mathrm{P}-\mathrm{P}^{\prime}$ & Floating TS & 10.92 & 88.96 & 13.14 & 133.44 & Safe \\
\hline
\end{tabular}

Case 3 - Combined Shell and Water Box Side Pressure

\begin{tabular}{|c|c|c|c|c|c|c|}
\hline SCL & Location & $\begin{array}{l}\text { Membrane Stress } \\
(\mathrm{Pm})(\mathrm{MPa})\end{array}$ & $\begin{array}{l}\text { Allowable } \\
\text { Limit (MPa) }\end{array}$ & $\begin{array}{l}\text { Membrane + Bending } \\
\left(\mathrm{P}_{\mathrm{L}}+\mathrm{Pb}\right)(\mathrm{MPa})\end{array}$ & $\begin{array}{l}\text { Allowable } \\
\text { Limit (MPa) }\end{array}$ & Comment \\
\hline $\mathrm{A}-\mathrm{A}^{\prime}$ & Opening Plate & 7.94 & 138.00 & 18.67 & 207.00 & Safe \\
\hline $\mathrm{B}-\mathrm{B}^{\prime}$ & Opening Plate & 7.95 & 138.00 & 17.91 & 207.00 & Safe \\
\hline$E-E^{\prime}$ & Opening Plate & 17.80 & 138.00 & 21.16 & 207.00 & Safe \\
\hline$Q_{-}-Q^{\prime}$ & Opening Plate & 22.46 & 138.00 & 29.08 & 207.00 & Safe \\
\hline $\mathrm{R}-\mathrm{R}^{\prime}$ & Opening Plate & 21.33 & 138.00 & 25.87 & 207.00 & Safe \\
\hline $\mathrm{T}-\mathrm{T}^{\prime}$ & Opening Plate & 17.68 & 138.00 & 18.93 & 207.00 & Safe \\
\hline$F-F^{\prime}$ & Fixed TS & 1.60 & 88.96 & 1.80 & 133.44 & Safe \\
\hline $\mathrm{G}-\mathrm{G}^{\prime}$ & Fixed TS & 3.60 & 88.96 & 3.74 & 133.44 & Safe \\
\hline $\mathrm{H}-\mathrm{H}^{\prime}$ & Fixed TS & 2.40 & 88.96 & 10.13 & 133.44 & Safe \\
\hline $\mathrm{I}-\mathrm{I}^{\prime}$ & Fixed TS & 2.42 & 88.96 & 2.45 & 133.44 & Safe \\
\hline $\mathrm{J}-\mathrm{J}^{\prime}$ & Fixed TS & 2.00 & 88.96 & 22.32 & 133.44 & Safe \\
\hline $\mathrm{N}-\mathrm{N}^{\prime}$ & Floating TS & 24.11 & 88.96 & 24.66 & 133.44 & Safe \\
\hline $\mathrm{P}-\mathrm{P}^{\prime}$ & Floating TS & 14.95 & 88.96 & 19.29 & 133.44 & Safe \\
\hline
\end{tabular}




\section{Conclusion}

The design of the Opening Plate, The Floating Tube Sheet and the Fixed Tube Sheet are safe for the loading conditions specified

\section{References}

[1]. Ramesh K. Shah, D. P. (2003).Fundamentals of Heat Exchanger Design. New Jercy and Canada: John Wiley \& sons Inc.

[2]. David Heckman, Davis, Gene Massion, Mark Greise, Finite element analysis of pressure vessels, MBARI, 1998.

[3]. Eugene F. Mgyesy, Pressure vessel hand book, pressure vessel handbook publishing Inc., fourth edition, 1978.

[4]. K.satoh, J.Kubota, J.Kashiwakura and S. Maruyama, Structural integrity of heat exchanger component for top entry loop type FBR, Elsevier science publisher,Vol.E, 1993.

[5]. Krishnamurthy CS ,Finite element analysis 2nd ed. Tata Mc-Graw Hill Book Company ,New Delhi , 1994.

[6]. David Heckman, Davis, Gene Massion, Mark Greise, Finite element analysis of pressure vessels, MBARI, 1998.

[7]. J.Chattopadhyay, H.S.Kushwaha and E.Roos ,Some recent developments on integrity assessment of pipes and elbows, Int. J. of solids and structure,Vol.43,Issue 10,pp 2904-2931, 2006.

[8]. 15th Australasian Fluid Mechanics Conference, Sizing of air-cooled heat exchanger, 2005.

[9]. M. T. Gonzalez; N. C. Petracci; M. J. Urbicain, Air cooled heat exchanger design using successive quadratic programming, J. of Heat transfer engineering, Vol 22, Issue 3, pages 11 - 16, 2001.

[10]. P.Chellapandi, A Biswas, S.C.Chetal, S,B.Bhoje ,Theoretical and experimental assessment of structure integrity of primary pipe,IAEA-TECDOC,2003.

[11]. Z.F.Sang, Y.J.Lin, L.P.Xue \& G.E.O. Widera , Limit and Burst Pressures for a Cylindrical Vessel With a 30 deg-Lateral 0.5), J. of Pressure Vessel Technol. ,Vol127,Issue1,pp 61-70,2005.

[12]. Yong Wan Kim, Dong Ok Kim, Jae Seon Lee, Suhn Choi and Sung QuunZee, Thermo-mechanical simulation for nozzle shell \& tube heat exchanger of once-through steam generator by experiment and finite element method Int. J. of pressure vessel and piping ,Vol. 82, Issue 8, Pages 602-609, 2005.

[13]. ASME (American Society of Mechanical Engineers) code sec VIII Div-I Edition 2004 Addenda 2006.

[14]. ASME (American Society of Mechanical Engineers) code sec VIII Div-II Edition 2004 Addenda 2006.

[15]. API (American Petroleum Institute) 661 for air cooled heat exchanger, Edition 2006.

[16]. Raymond K. Yee and Mike Kapper, A Structural Integrity Assessment Methodology for Pressurized Vessels, J. Pressure Vessel Technol. Vol 128, Issue 4, 541 (6 pages), 2006.

[17]. Dong Stelling ,FEA Analysis of a Large Nozzle to cylinder shell Junction, Carmagen Engineering, Inc.2008.

[18]. www.Google.com

[19]. www.wikipedia.org

[20]. www.geiind.com 